\title{
Kidney Wilms Tumor
}

National Cancer Institute

\section{Source}

National Cancer Institute. Kidney Wilms Tumor. NCI Thesaurus. Code C40407.

An embryonal pediatric tumor of the kidney which may also be seen rarely in adults. The peak incidence of Wilms tumor is between the second and fifth year of life.

Microscopically, it is composed of a mixture of cellular elements (blastemal, stromal, and epithelial). The most common sites of metastasis include the regional lymph nodes, lungs, and liver. 